\title{
Sensing Feeling Alive: Attentiveness to Movements in/with Embodied Teaching
}

\author{
Marit Honerød Hoveid ${ }^{1}$
}

Accepted: 5 March 2021 / Published online: 23 March 2021

(c) The Author(s) 2021

\begin{abstract}
This is an explorative work on teaching. The understanding of teaching that I use in my work is that teaching is action, it happens in the present - here and now. So, while teaching refers to shorter timespans, education in this understanding refers to timespans that are of a longer duration, meaning education is communication between generations (Hoveid and Hoveid 2019). The notion of teaching I explore draw from experiences, for my own part between nature, dog and human. These are experiences of sensing where one flows through and interconnects with others, so that boundaries are difficult to discern, and hence boundaries are not the point, but rather how sensing bodies and 'movements between' create experiences that are constitutive of who we become both as dog and human, in/with nature. Here I am not referring this to learning, as is usual in the equation "teaching and learning". This does not mean learning is irrelevant, but rather that it is such an encompassing concept I cannot deal with it satisfactorily in this article. Also, I go beyond what is commonly understood as learning, in terms of making a change in someone's cognitive or emotional structures. This article explores the kind of experiences our sensing body furnish us with and how these transfer to memory, in the here and now bodies sense, and how this creates memories. I argue this is especially important to recognize in teaching, but seldom addressed. I suggest we pay more attention to these experiences of sensing and how it becomes part of individual and collective memories. To me this is a vital and integral part in all teaching, in the present.
\end{abstract}

Keywords Teaching $\cdot$ Nature $\cdot$ Animal $\cdot$ Human $\cdot$ Sensing $\cdot$ Memory $\cdot$ Movement . Participation $\cdot$ Collaboration

Natural beauty suffers the same fate as does education: It is vitiated as the inevitable consequence of its own expansion" (Adorno, 1997, p. 98).

Marit Honerød Hoveid

marit.hoveid@ntnu.no

1 Department of Education and Lifelong Learning, Norwegian University of Science and Technology, 7491 Trondheim, Norway 


\section{1.'Living all The Way Through'}

"Something moves between me and it. Place and mind may interpret it till the nature of both is altered. I cannot tell what this movement is except by recounting it", writes Nan Shepard, in the book The Living Mountain (1977/Kindle edition 2018). Here she recounts her relationship with the Cairngorm mountains of north-east Scotland. These mountains are never the same, they change and challenge, thrill and scare, depending on the time of year, the weather, who is there together with her to sense and become part of the mountains, rivers, lochs, flora and fauna. My own mountain area is in Norway, in Rondane (but also in the north of Norway, Finnmark). This is an area I return to many times every year. I have experienced how these mountains challenge my senses and give me experiences I come back for time and time again. Like last winter when we were cross-country skiing over a mountain stretch, at about $1000 \mathrm{~m}$ altitude, the weather was grey, the light very flat, so that for a while we saw very little of the contours of the landscape in front of us - cross country-skiing then is difficult for you can no longer trust your eyes - you have to sense the contours of the landscape - use your other senses and adapt your body accordingly in order to move forward on the cross-country skis. The sensations this gives, accomplishing to move in/with the landscape, makes me feel alive. My experiences resonate with what Robert McFarlane writes in the introduction to The Living Mountain:

Her [Shepard's] book is a hymn to 'living all the way through': to touching, tasting, smelling and hearing the world. If you manage this, then you might walk 'out of the body and into the mountain', such that you become briefly 'a stone ... the soil of the earth' And at that point then, well then 'one has been in'. That is all writes Shepard, and that 'all' should be heard not diminutively, apologetically, but expansively, vastly." (loc 312)

This article addresses teaching, exploring what the presence of bodily sensations in teaching might mean. The theme I focus in on is the sensing body in relation to participation and collaboration through an engagement with my own sense experiences from dog mushing and sled dog racing. I address these experiences through the theories of the mingling of bodies by Michel Serres (1985 2016) and ideas about the constitution of memory by Henri Bergson (1991). The role nature plays in this is addressed foremost by Nan Shepard and the way she recounts the living mountain. My own reference to being in nature with dogs is a way of telling you that these movements of the sensing body can be experienced and that they can give feelings of accomplishing something together. What I am first and foremost concerned with is how teaching opens spaces for the ones present to be alive. If this does not happen and teaching instead closes these spaces it risks becoming lifeless or dead, I contend. My experience is that teaching is easily turned into instrumental activities that are experienced as meaningless for those involved. Keeping teaching alive involve those who are present in teaching: teachers and students. It is what happens in these spaces in-between (Hoveid and Finne 2014) that concerns me here.

The statement I elaborate upon in this article is that the sensing of participation and collaboration need spaces to appear in teaching (as action/doing). The article address this through three topics:

- Working together-the sensing body

- Sensing and memory: "At the center of action, is my body"

- Creating collective memories of participation and collaboration 
My own reference to being in nature with dogs is a way of telling you that these movements of the body can be experienced and that this sensing of accomplishing something together is real. What I am first and foremost concerned with is how we (constantly) revive teaching so that teaching itself is also kept alive. If it lacks spaces for the senses to expand, that is - has become lifeless or dead, and I believe this is a real threat, then much is at stake.

Keep in mind, this work is foremost explorative and represents a philosophizing about the relationship between sensing being alive, as attentiveness to movements in/with teaching. And remember, in this context participation and cooperation is read and discussed in light of bodily sensing.

\section{Working together: the sensing body}

Let me now take you into another way of being in nature, in a way more extreme, still addressing sensing and movement, but this time together with dogs. In March 2018, I raced with a team of 14 dogs inFinnmarksløpet. ${ }^{1}$ We travelled $1200 \mathrm{~km}$ over the Arctic tundra in Finnmark, in northern Norway. This was a long journey where I learned a lot about myself, and more importantly were the doges taught me things and expanded my way of sensing and consequently of acting (doing things) — that will be with me forever. Something happened between us. To give you a glimpse of this, let me tell you about one experience.

At nighttime, towards the end of the race (we had by then travelled more than $1000 \mathrm{~km}$ ) we came to a lake, Jesijavri which is about $30 \mathrm{~km}$ long. It is a huge vast white void when you travel on it in snowy, windy weather-as it was this night. Many teams have been stranded on this stretch. On the lake the trail was extremely wide, and because so many snow machines had made tracks this made orientation difficult both for the dogs and me. There are markers that show the trail, but on the lake there were many snow drifts, so, to make the sled glide easily, we had to go in zig-zags between the drifts that covered the lake like a patchwork. The drifts consisted of a type of snow that is very coarse (Norwegian: fokksn $\phi$ ) and it makes the sled glide poorly. Between the drifts however, the trail was hard and icy, and here the sled glided easily. I had never been in a situation like this with the team before -where we had to go in zig-zags and not follow the markers-so what then? I cannot tell you how it happened or how we started cooperating on this task-we just did. My two leaders were extremely clever. They understood quickly that the snowdrifts made the sled slower and heavier to pull, so they were looking for the best trail themselves. Since I stand up and have a headlamp, I see further up the trail than they do, so I could tell them 'now go right', 'now go left', and they understood that I gave good advice-so they also listened to me. Sometimes they saw and smelled (probably smelled more than saw) the trail for themselves, and I did not have to say anything. For about $30 \mathrm{~km}(2,5 \mathrm{~h})$ we did this. It was like a dance as we moved forward together. We sensed and worked together, and the dogs gave me some insight into what they are able to accomplish. For me the sensations of moving together with the dogs-in the night - in this big vast void is truly indescribable.

This cooperation between human and dogs was mainly dependent on us sensing each other as we travelled together. What we accomplished together was especially dependent

\footnotetext{
1 Finnmarksløpet is a long distance sleddog race. You start with 14 dogs, if some are injured or get ill, they are taken out of the team and cared for. See: https://www.finnmarkslopet.no/home/.
} 
on the lead dogs, but it was really dependent on the whole team, and it entailed a sort of cooperation where one always must sense the movements of the other. This kind of working together is about something else than accomplishing an objective, not meaning that objectives are unimportant, but that putting a single focus on objectives as learning goals or outcomes divert attention from what happens here and now. The event I refer to above, highlights the sensations created in the present - when we work together. Sensing in this kind of working together is also important in teaching (and learning). Let us explore this sensing in the here and now further.

Michel Serres, in The Five Senses, A philosophy of mingled bodies (1985/2016) writes about language and he reflects on an event where he was stung by a hornet during a lecture and that he did not change his voice or intonation while lecturing. He claims that "The speaking body, flesh filled with language, has little difficulty in remaining focused on speech, whatever happens. Words fill our flesh and anæsthetize it" (p. 58), he writes. The experiences I have referred to above cannot simply be re-told. Words cannot fully depict the emotions, the sensations of the flesh that recount them so that you could sense what happened there and then, in me, in the dogs - between us. In this I think Serres is right. Words usually do not contain in them these experiences of the flesh, the sensations of what the body does. Maybe that is not the point either. Words and sentences can make stories, but the living mountain, the living here and now with a team of dogs moving in nature is about something else. "Stories are told, they are not lived" Louis Mink, reminds us (in Ricoeur 1994, p.159). Let's remember that!

Teaching is difficult to conceive of without speaking - without words, but it is the case that in teaching there are also bodies, ${ }^{2}$ sensing bodies. Teaching, in an action-oriented theoretical approach $^{3}$ has to do with what one does with words, as a body speaking. I am not so concerned with the speaking and telling aspects of teaching in this article, but instead with the fact that both teachers and students have sensing bodies that interact. This means their speaking is entangled in various kinds of bodily sensing, creating movements in and between sensing bodies. These movements can create spaces in teaching where both students and teachers can feel alive.

An environment of working together is paramount in teaching. On the sled - I can command and ask dogs to go in certain directions, but we work together. If we did not - it would fall apart. My image of the dogs and me on the mountain is an image of what sensing and working together entail. In teaching I argue that the sensing body is present in some form or other even though it may have become aenæsteziced. When this happens, teaching disintegrates and becomes void of life. Without a space for the expansion and connection with others through our senses, teaching will be profoundly affected. You may call what I am talking about atmosphere, learning environment, trust and so forth. What I want to highlight is that the bodies present are sensing bodies that are either given space to expand or are told to shut down.

The sense of being alive is something humans are dependent on. In modern life, where technologies are predominant, some humans seem to have forgotten or lost connection with

\footnotetext{
${ }^{2}$ I single out teaching from the equation teaching and learning, knowing that they are always intertwined. What I hope to achieve by this is a reconceptualization of teaching. I want to move our conceptualization of teaching towards what happens in the here and now - to sensing bodies in a classroom.

3 This approach is based on reading Paul Ricoeur's Philosophy, see Hoveid \& Hoveid, 2019.
} 
being in nature. ${ }^{4}$ As part of this I think it is worth exploring further why the kind of sensing I describe with dogs in nature creates a deep sense of being alive and discuss why these sensations might be different from mediations through a piece of art or through a human-made aesthetic expression. This is not about downplaying aesthetics, but I want to move the discussion of humans with others to a different domain. My cooperation with dogs in nature points to a place and time where there is a dependency on the other, and where cooperation, as moving together, is paramount for life itself. I elaborate this through a way of thinking the sensing body in the here and now - how one can sense an extension of oneself with others if others also has a space to expand their sensing body. Just as when the dogs and I traveled across Jiesijavri (lake) in Finnmark, in that space and time all our bodily senses were extensions towards each other as we worked together.

\section{Problematizing Teaching Through the Aesthetics of Natural Beauty}

I approach teaching through an action-oriented approach built on the philosophy of Paul Ricoeur (Hoveid and Hoveid 2019). This action-oriented approach relates to Ricoeur's phenomenology and literary hermeneutics. This provides a background for this text. There is a tendency to understand teaching as an instrument, as a transmission of information from the one with more knowledge to another who is less knowledgeable. Framing teaching as action, as that which happens in the here and now, means one must pay attention to teachers' and students' actions, their inter-actions and re-actions. In teaching, teachers and students use words, and they make things happen with words. However, it is not what the interlocutors of the classroom do with words (even if this cannot be distinguished from other bodily actions and behaviors) - that matters here. Rather my focus is on sensing in teaching and that the movements this creates have profound impact on those who are involved. Over time, bodily sensing of what happens in teaching creates individual and collective memories (A point I return to below). My experience is that in teaching this is seldom acknowledged, simply because the way sensing creates individual and collective memories are not seen as part of teaching and of what teachers learn to pay attention to.

In order to grasp how sensing influences us as humans, and the different layers it creates, a discussion related to natural beauty, by Adorno (1997) is helpful. The way nature and natural beauty was ruled out of aesthetic experience can give an idea of a distinction that is established in western culture. This is a development within aesthetics where the superiority of the human subject leaves this subject void of what it is at the same time dependent on. This means that within aesthetics the human subject has lost connection with nature.

Along the trajectory of its rationality and through it, humanity becomes aware in art of what rationality has erased from memory and of what its second reflection serves to remind us. The vanishing point of this development - admittedly an aspect only of modern art - is the insight that nature, as something beautiful, cannot be copied (Adorno 1997, p. 92).

\footnotetext{
4 This is by no means intending to romanticize nature - nature can be beautiful and brutal, she can be scary and unforgiving - and giving. Today we are at the verge of having ruined our natural habitats as humans - and humans will suffer, along with a lot of other species, from this. This is one reason I think that experiences of relationships with mountains, rivers, lakes, trees, beaches and dogs is important not to forget.
} 
Nature, and with it, natural beauty as something inherent to aesthetics, as something experienced, is relegated to that which is other, that which can be dominated and usurped-and henceforth made available for production, argues Adorno. With this " $t$ t]he resistance to empirical reality that the subject marshals in the autonomous work is at the same time resistance to the immediate appearance of nature" (p. 90). Something happened with the human subject's understanding and relation to nature when freedom and human dignity were prescribed to the subjectivity of the human being (and we could also add its superiority).

Nature became that which humans could free themself from. At the same time nature has always dominated human beings with fear and confronted with the forces of nature human beings have grounds for being fearful. According to Adorno this is what the subjective and rationalized consciousness tried to overcome. The "genius, once it has become aware of itself, is no longer satisfied with natural beauty" (p. 91). Losing this empirical awareness connected with nature has also had consequences for education, and hence for teaching. This, I believe, is exposed in the instrumental understandings of teaching as transmission (as something passed on from teacher to student). This connotation of teaching and learning is recognizable and strong in dominant understandings of education, especially in the era of 'what-works' in education (Biesta 2010; Steiner-Khamsi 2013). When teaching is about delivering a message, a message that contains a given content that the student must absorb, the teacher is just a messenger, and s/he does not really have to be involved in relations with others (including student others) (Hoveid and Hoveid 2019). In line with the deficit model explained by Rancière in the Ignorant Schoolmaster (1991), a teacher's actions in teaching is then understood as a transfer of a given content from herself as more knowledgeable to the students as less knowledgeable. Teaching is simply a production (of learning outcomes) and probably not distinguishable from the production of art, from cultivation, if we follow Adorno's critique (1997).

In teaching, here and now, things happen, bodies interact and sense. This in turn creates images of what happens, what Bergson calls memories (1991). In teaching better attention could be payed to the relations of what happens in interactions between bodies, and the images these bodies retain. The patterns this creates will determine the social interaction. A lot of what happens between students and teachers is forgotten, but it does not necessarily go away. A student who senses that a teacher's body turns away and avoids contact with him/her, will probably try to find ways of avoiding any close contact with the teacher. So, in teaching a teacher can pay attention to more than the relation that exists between the students and the subject matter, a teacher must also pay attention to the ways in which the sensing bodies communicate with each other. Everything happening in a classroom becomes part of an individual and collective memory-for better or worse, or for good or evil.

With what options does this leave the teacher? If a teacher has shut her senses off, her attention will mainly be directed towards how she can deliver the subject matter. Then her re-presentation of the subject matter could be equated with the reproduction of a piece of art which tries to represent the natural beauty of a landscape. Her actions become reproductions of something not present - a detached subject matter. Teaching then risks becoming a stultifying (re)production (devoid of life) of knowledge. A lack of attention towards

\footnotetext{
${ }^{5}$ In his discussion of natural beauty Adorno shows how this beauty, as in a robin's song after rain shower, is also imbued with something frightening-in short, something uncontrollable. Natural beauty belongs to a myth, that always also brought with is something to be fearful of, something scary.
} 
the presence, of what teacher(s) and students are doing and of what happens here and now, like the hornet stinging while speaking (Serres 1985/1916), then becomes the epitome of teaching without presence - then words ancesthetize. Teachers' and students' bodies sense themselves and one another, but they can easily shut their awareness to this off - by way of using words (Ibid.). If this happens it will influence the way bodies sense in the classroom. It will influence the senses of engagement with each other, the senses of reciprocal participation. If sensing is shut off, the risk is that engaging ways of participation and collaboration will most likely vanish.

"[Nature's] beauty is best known through its unconscious apperception; in the continuity of such perception natural beauty unfolds, sometimes suddenly", Adorno writes. (1997, p. 95). Could natural beauty, or rather the experience of nature as an image of the empirical reality of a classroom, help develop an understanding for the necessity of paying attention to bodily sensing in teaching? I believe this is possible, not as a technique, but as an attention towards unmediated experiences (like those in nature) of sensing in a classroom. When you have witnessed a teacher, who displays this kind of unconscious apperception, one is immediately struck by what she does; how she moves in the room and shows attentiveness towards the other (students) and how students respond and all seem alive and present in relation to her and each other when communicating (see Hoveid and Hoveid 2019, pp. 29-45).

What I have argued thus far is that in the empirical reality of teaching, bodies interact, and that this sensing is of importance. This is worth paying attention to in order to open spaces in teaching for participatory and collaborative ways of being alive. Sensing creates memories that linger between bodies. If we agree that in teaching sensing bodies interact, then we can state that body memories are created. In teaching, memory is too often given a very limited task. It is usually described as memorization, as a cognitive faculty bound to reiteration of factual knowledge. Let me instead proceed by giving attention to other functions for memory in teaching.

\section{Sensing and Memory: "At the Center of Action, is My Body"}

I listen a lot to audio books when I am out riding my bike. Sometimes when I must wind back to where I left the book last, I hear through passages and I remember exactly where I was, when I heard the words last. So, my body remembers two independant sense impressions, one connected to the words I listened to and the other is the impressions my body received from the places I passed bicycling. Then, these two sense impressions are connected without me consciously retrieving them.

The sub-title of Michel Serres book is a philosophy of mingled bodies. Stephen Connor writes in the introduction (Serres 1985/2016, p. 3) "For Serres, ..., the senses are nothing but the mixing of the body, the principal means whereby the body mingles with the world and with itself, overflows its borders,". And, we are warned that in the reading of this text we must be prepared to enter a maze, where words are not necessarily meant to analyze and make separations - as we strive for in academic writing. What intrigues me about this text is that I can find a way of perceiving the sensing body that make me curious. It resonates with me and the dogs in nature.

A living body is a body with a memory; it is impossible to perceive any sensation without them also becoming part of a memory. A body remembers. It is that kind of experience when you are out walking, maybe somewhere you have not been for a long time, and maybe have forgotten about the place. Then suddenly images flash by, you sense 
something about the place that is familiar. Your body has perceived something there and then, it knows that it has been here before. Peso a very good friend of the family, passed away a little over a year ago. He taught me about how he sensed his surroundings and how he oriented himself by what he sensed. He was a lead dog and he led me in several races and once in the shorter version of Finnmarksløpet - (only) $500 \mathrm{~km}$. The last checkpoint we came into is called Joatka ${ }^{6}$ and shortly before we arrived there, I saw it on Peso - his whole body reacted - and I said- "you know where you are now Peso" - and he smiled as he turned back to look at me (dogs do smile!). Shortly after we were at the checkpoint, he turned to go into the place we had rested going out, and I stopped him - and said - no - we are going home now. We made a very short break to sign in and I gave the dogs some snacks, and then Peso jerked the whole team with him, and we headed down the trail (this is usually a difficult maneuver-the dogs want to go and rest where they rested earlier in the race). Peso knew he was close to the end of the race, and his whole body and attitude told the other 7 (young and inexperienced) dogs in the team (and me) that he was confident that we were going to make it - he knew we were almost at the end of the race - and his body expressed this to the rest of us.

A body remembers, memories are stored, they re-surface. When and how they re-surface we do not necessarily have control over. They re-appear, not necessarily because we consciously recall them although some memories of course can be. Here I am more concerned with the memories that our body retains, that our body remembers and that weave themselves into human actions, that become part of individual and collective memories.

How memory resurfaces for dogs I cannot tell you, but I know that they have memories, and that they behave according to the memories they have. "There is nothing in the mind that has not first been in the senses (nihil in intellectu quod non prius in sensu)" writes Connors (in Serres 1985/2016, p. 5-6) with reference to how Serres uses this phrase, often said to originate from Aristotle, as a way of propagating ideas rather than conjoining them. In other words, how sensing and mind are interconnected is not simply a matter of a linear movement from the one to the other. What Connors writes is more in line with my own interpretation of this relation:

So, for Serres, the senses are not islands, or channels, that keep themselves to themselves. They do not operate on different frequencies, in different parts of the waveband, but are subject to interference - they are even interference themselves (Ibid p.7).

If sensing creates interferences in body and mind, and this is expressed in action (i.e. in teaching) and becomes part of something individual and collective, then this requires attention. The idea that mind alone is prevalent in understandings of teaching, needs serious questioning. Instead of separating mind from sensing we could instead pay attention to the way sensing creates memories and operates in teaching. In other words, how sensing as interferences are created and re-created.

This implies that what is sensed will reappear later. Let me address this via Adorno (and Bergson). Adorno (1997) writes

Nature's eloquence is damaged by objectivation that is result of studied observation, and ultimately something of this holds true as well for artworks, which are only completely perceptible in temps-durée, ... (p. 95).

\footnotetext{
${ }^{6}$ In Mushing, dogsledding, a checkpoint is a place where you usually stop to rest, water and feed the dogs.
} 
Here Adorno refers to Bergson (1991). The duration of time (temps-durée), in a Bergsonian reading refers to movement, and deals with that which is retained in the memory images from those events one is involved in, what one senses as a (human) being. In the event, here and now, there is only life, so to speak.

Let us elaborate an understanding of teaching, as here and now, a bit further with Bergson to tease out some of the complexities this entail. According to Bergson (p.13) it is precisely memory that we find at the intersection between mind and matter. Mind, referring to that which the human is a bearer of (a soul, a brain) and matter as that which is there in the outside world, that which the idealist calls representation and the realist calls $a$ thing. Matter according to Bergson is an aggregate of images (Ibid.). Bergson is occupied with the relation between matter and memory. He is aware of the dualistic interpretation this may cause, like the profound dualism between body and mind. But he proclaims to overcome this by a model of understanding this relation which is much more dynamic. This short article can by no means reflect the complexities Bergson is working with in his account of human memory. My references here are only to a very limited aspect of memory and how memory images are retained, those images human beings (and dogs to a certain extent) carry with them (retain) from life lived. These images are determining factors for the actions of that being in his or her relations with others.

Bergson reminds us that there are connections which are 'produced' through life, in our bodies, related to time and memory. In relation to the psychic life of the human he writes: "There are then, in short, diverse tones of mental life, or, in other words, our psychic life may be lived at different heights, now nearer to action, now further removed from it, according to our attention to life" (p.14, italics in original). The idea that the human could, as shown earlier with Adorno, raise him/herself above life (or nature) is by this thoroughly rejected. But, attention to life could become anæsthetized, to use Serres contention.

To try to grasp these relations between life and memory I return to action. What is here called relations could just as well be named movements. "At the center of action, is my body", writes Bergson (p.20). This body operates between the excitations it receives from the outside and the movements it executes from the inside. And, he formulates the following: "All seem to take place as if, in this aggregate of images which I call the universe, nothing really new could happen except through the medium of certain particular images, the type of which is furnished me by my body" (p.18, italics in original). In other words, this body and its memories set certain boundaries for the human being. It creates limitations for perception (sensing) and action. It means that human perception (sensing) is framed by one's memories, we cannot speak of perception as pure. ${ }^{7}$

Bergson argues throughout the workMatter and Memory (1991) that there is no such thing as pure perception. Given that the idea of pure perception, ${ }^{8}$ derived from psychology, is rejected, should impact our take on action. Pure perception builds on the idea that something is apprehended without the interference of a sensing body. According to Bergson, this cannot be. If communication in the space of a classroom was structured as a "pure"

\footnotetext{
${ }^{7}$ I do not intend to discuss perception (sensing) in this article. The main point I derive from Bergson is that there is no such thing as pure perception. Humans are framed by what and how they sense and the memories that are retained from an event will frame perception (erkentniss). The movement between inside memories and what an individual perceives from the outside, the movements this creates are important.

8 The idea that one can perceive directly (without mediation) from an empirical reality, still seems to linger somewhat in common takes on perception. For Bergson, this refers to a discussion with Psychology at his time.
} 
collection of spoken words - information-directed from the teacher to singular students, then these words will most likely anæsthetize. Then teaching is an instrument - it is teaching without life.

For life to remain in teaching, environments where individuals' senses are given space to expand are necessary. This means teachers attentiveness to different layers of communication in teaching affects the possibilities for processes that are geared toward an aggregation of memory images of participation and collaboration to be distributed and shared among the participants. Over time such memory images determine teaching.

\section{Creating Collective Memories of Participation and Collaboration}

When I have worked with a group of dogs, what I always recognize is that we are making together something (memory images) that lingers between us (temps-durée). I can choose to pay attention to this or not. When I pay attention to it, I always seem to receive more responses from the dogs. These responses are confirmations that my sensing of the dog (the other) is answered, my sensing is reacted and acted upon - and this goes both ways - always, and it creates memory images. Dogs react to body language. It you pay attention to and recognize how your body is read/interpreted, you may see that a dog checks for a "permission" (running away from the pack is not accepted). So, when we are out walking as a large group, one of the outgoing dogs might look up at me - see if I (their human) am attentive - and based on how it perceives my attention - the dog makes a choice - stays with the group or takes off on a detour. This kind of communication, happening silently, always develops within a group working together. And furthermore: "We assert, ..., that if there be memory, that is, the survival of past images, these images must constantly mingle with the perception of the present and may even take its place". (Bergson 1991, p. 65-66). So, if the dog senses that I am not paying attention, s/he might use the opportunity to run away but if I am attentive, if I assert back with my body and gaze, 'no! it is not ok to run off' $-\mathrm{s}$ /he stays and hopefully remembers to stay with the pack also in the future. Depending on the awareness you have of what your body communicates you will always assert yourself within any collective of other bodies, and other will react according to what they sense in this communication. Communication from what we sense creates memory images. Depending on what is communicated, this can establish anything from domination (hierarchy) to collaboration (participation).

When memory images are created, as in the example above, an experience of running off by him/herself may be what the dog has retained from our walks together, and so this is what s/he might seek to repeat every time we go for a walk. What Bergson argues is that there is only a difference in degree, not in kind, between perception and memory (Ibid.). The mingling of memory images in a larger group of humans in a classroom are difficult to discern, as it is within a group of dogs. So many things happen at the same time. There is no way this can be controlled, and that is not the point either. My point is that as educators we could pay better attention to these processes of bodily sensing and memory. Also, a teacher through her sensing could then try to act so that the group as a collective produces memory images that are pro-social, of participation and collaboration. I believe the opposite is more often the case in classrooms where a teacher is seen as someone who should exert management skills and have command over the students. Then power and control, defined within bureaucratic rules, often gets in the way of creating a pro-social community. 
Bergson talks of two types of memory, the one that repeats and is stored as a motor memory, while the other one imagines (p. 82, Italics in original). To exemplify this, he tells about an example of a dog and his master. Their behavioral patterns gradually build up between them. So, when the master returns home the "images of the past overflow into the present perception" (Ibid.); but Bergson contends that the dog's recognition of the master, the eagerness and happy wagging of the tail in the present is lived, rather than thought. This understanding of action as living in the present, even though these actions are representations of former actions, creates the possibility for imagination in the present. It does not mean every action creates imagination, some are merely repetitions that uphold a daily routine. But without the living in the present, without actions creating imagination, teaching is stultified, in plain words repetitive - instrumental.

In a classroom senses are mingled as bodies are mingled in ways that are unforeseen and uncommendable - that is how it is. But to pay better attention to life in teaching could possibly help many students from shutting themselves off from what goes on in the classroom. If students stop reacting in teaching, if they show no engagement with what the teacher wants them to do then maybe this relates to what has happened before in class. If the words of the teacher have anæsthetized, if teaching is stultifying, then a student might have to reject what goes on and instead protect him/herself and seek life outside of teaching.

Memory of participation and collaboration - in teaching - is determined by what one senses here and now. Saying that sensing is determined by memory means perception is never neutral or unmediated (no pure perception). Thus, students' memory of participation and collaboration from teaching will have profound impact. Most children spend 10-13 years in school. This entails long term relationships between teachers and students. How movements between sensing bodies are played out in teaching, and especially what teachers do, matter. My preoccupation is that it matters in terms of how one will come to understand participation and collaboration. If, say, a student leave school with no memory of participation, of belonging and working together, and therefore with little possibility of re-imagining it - then some basic requirement for human co-existence is put at risk.

\section{Participation and Collaboration-Constitutive Aspects of Teaching?}

What kind of memories of participating and collaborating are created in teaching? Can teaching create movements between sensing bodies where one's sensing is an extension of one's body towards others? Here, in the last part of this paper I return to the title: Sensing Being Alive. When addressing this in relation to teaching I want to point out what is at stake. Most people have experiences from teaching, from doing things in a classroom. What kind of memories we have are individual, but these are the memories that make us recognize teaching and they are the memories we relate to 'what teaching is'. Many of these memories are part of our bodies and they may only be triggered by our senses - a smell, a touch. I argue that the present, in the acting of teachers and students, must create memories of participation and collaboration. The sensing of being together (participation and collaboration), as a movement between bodies, must be established. If not, how could one recognize it as part of teaching?

Some years ago, I visited a classroom in Alaska (Hoveid and Hoveid 2019). In one corner of the classroom there was a rocking chair, on the floor a carpet, the corner was encircled by bookshelves and a fish tank in the window with small birch trees (a science project). Every day the children gathered on the floor, each with a copy of the book from 
which the teacher read aloud. The sense of togetherness, sitting together side by side, your foot or shoulder close to someone you like, listening to words being read, following the reading of the words in the book you hold in your own hands, the smell of books in the room, and so much more... This reading every day was a space for the senses to expand.

In the empirical reality of teaching, bodies interact, not unlike the time I travelled across Jiesijavri with a team of dogs. Commonly, in teaching one is not so acutely aware of the way bodies interact and communicate. My concern is that, in teaching, a sensing of participation and collaboration must be created. This is a normative aspect in my take on teaching. Since teaching in school usually happens within larger groups of students and teachers, this is a place where participation and collaboration are learned - or not. This means that teaching could become a place where only competition (as a hierarchal ordering) is communicated. Then one's sensing of participation and collaboration usually deteriorates.

Sensing being alive in teaching refers to moments when imagination is sparked, where a sense of community and belonging can arise. It refers to those moments when stretching out towards the other is acted and re-acted upon in ways that extend the sense of being alive - of living. I am not saying that competition, of being the best one, cannot create an individual sense of being alive, but following my argument here, being with other(s) is a more basic form of life. It is the form of life telling that one belongs and never can separate oneself from others.

I have tried to show how both human and dog in nature can experience sensing of being alive. I have emphasized that experiences in nature can create those movements between bodies that contain in them a type of sensing that I believe we are dependent on as humans (and as dogs). Teaching takes place in classrooms in schools in urban and rural communities. It is by no means the same environment as the living mountain re-counted by Nan Shepard, but maybe one could begin to see classrooms more like her mountain. Bodies are live but can become anæsthetized. I argue that the living (sensing) body needs space to expand in teaching.

When I started the long journey across Finnmarksvidda with dogs in the long race in 2018, I did not know them well, I had only met them a few times, and had run with some of them in training runs, but not all of them. Most of these dogs were young and had little prior race experience. I know that trust is paramount to finishing together, so I had to work on building trust between us, meaning, I had to do what I saw fit to gain their trust, if they were going to trust me-it is something they decide. But, as those of you who have owned dogs know, they are a trusting creature and, like humans, they are a pack animal. Also, my program, as the pedagogue I am, was to make this journey/race an experience of doing something together, of accomplishment and capability. For all of us this included learning about sleddog racing (mushing), and all that it entails, but I also had to make sure that we had an experience of this being fun. How do I know they did? I know it because they were "high" "the whole race/journey. A dog who has successfully done a whole race will remember this next time s/he is on that trail. And trust me, they know when they are in a race and they know where they are. In racing, up to half of the teams do not finish, not necessarily because of the dogs, but often because of the human behind them on the sled runners. S/he is usually the weak link, the one who is the reason the team does not finish. S/he is the one who has not worked on her/his being part of a team. If s/he has ceased to sense

\footnotetext{
9 The word here refers to how mushers describe their dogs - 'high' in this context means eager, happy, energetic, alive. The opposite is a dog with his head down, empty gaze, looking tired an unengaged (these dogs will stop running).
} 
the other's (dogs) presence, it will have an impact. My idea is that we can transfer some of this understanding of bodily sensing into classrooms and to teaching. Movements of sensing being alive between bodies in teaching is what I hope education can acknowledge.

Funding Open access funding provided by NTNU Norwegian University of Science and Technology (incl St. Olavs Hospital - Trondheim University Hospital).

Open Access This article is licensed under a Creative Commons Attribution 4.0 International License, which permits use, sharing, adaptation, distribution and reproduction in any medium or format, as long as you give appropriate credit to the original author(s) and the source, provide a link to the Creative Commons licence, and indicate if changes were made. The images or other third party material in this article are included in the article's Creative Commons licence, unless indicated otherwise in a credit line to the material. If material is not included in the article's Creative Commons licence and your intended use is not permitted by statutory regulation or exceeds the permitted use, you will need to obtain permission directly from the copyright holder. To view a copy of this licence, visit http://creativecommons.org/licenses/by/4.0/.

\section{References}

AdornoW, Theodore. 1997. Aesthetic Theory. London and New York: Bloomsbury Academic.

Bergson, Henri. 1991. Matter and Memory. New York: Zone Books.

Biesta, Gert. 2010. Good Education in the Age of Measurement. Ethics, Politics, Democracy. Boulder co. and London: Paradigm Publishers.

Hoveid, Halvor, and Arnhild Finne. 2014. 'You Have to give of yourself': care and love in pedagogical relations Journal of Philosophy of Education. 482246259 https://doi.org/10.1111/1467-9752.12069

Hoveid, Halvor, and Marit H. Hoveid. 2019. Making Education Educational. A Reflexive Approach to Teaching. Switzerland: Springer Nature.

Rancière, Jacques. 1991.The Ignorant Schoolmaster. Five Lessons in Intellectual emancipation. Stanford CA.: Stanford University Press.

Ricoeur, Paul. 1994. Oneself as Another. Chicago and London: The University of Chicago Press.

Serres, Michel. 1985/2016. The Five Senses A Philosophy of Mingled Bodies. London and New York: Bloomsbury Academic.

Sheppard, Nan. 1977/2018. The Living Mountain. Kindle Edition.

Steiner-Khamsi, Gita. 2013. What is wrong with the 'what went right' approach in Educational Policy? European Educational Research Journal. 11 (1): 20-33. https://doi.org/10.2304/eerj.2013.12.1.20.

Publisher's Note Springer Nature remains neutral with regard to jurisdictional claims in published maps and institutional affiliations. 